\begin{tabular}{|c|c|c|}
\hline & $\begin{array}{c}\text { Klinikal Sains } 8(1)(2020) \\
\text { JURNAL ANALIS KESEHATAN } \\
\text { KLINIKAL SAINS }\end{array}$ & KLINKAKALSAINS \\
\hline $\begin{array}{l}\text { UNIVERSITAS } \\
\text { ABDURRAB B }\end{array}$ & http://jurnal.univrab.ac.id/index.php/klinikal & 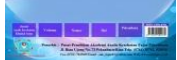 \\
\hline
\end{tabular}

\title{
PENETAPAN KADAR PEMANIS BUATAN (Na-Siklamat) PADA SELAI DENGAN METODE GRAVIMETRI
}

\begin{tabular}{llc} 
& $\begin{array}{c}\text { Hartini H., Jely Syaputri Simorangkir } \\
\text { Akademi Kesehatan John Paul II Pekanbaru } \\
\text { Jl. Permata I No. 32 Pekanbaru } \\
\text { hartini.tini214@ @mail.com }\end{array}$ \\
\hline Info Artikel & Abstrak &
\end{tabular}

Bahan tambahan pangan (BTP) berupa pemanis buatan umumnya dikonsumsi untuk tetap mendapatkan rasa manis pada makanannya tetapi tidak dimetabolisme

Sejarah Artikel: di dalam tubuh. Pemanis buatan siklamat mempunyai tingkat rasa manis yang lebih tinggi dari gula (sukrosa) dan harganya lebih murah. Kadar maksimum

Diterima Maret 2020 Disetujui Maret 2020 Dipublikasikan Juni 2020

\section{Keywords: \\ food additives}

sweetener, cyclamate, Kata Kunci: bahan tambahan pangan, pemanis, siklamat, selai, jam

\begin{abstract}
Artificial Sweeteners categorized as food additives are generally taken to provide sweet taste but are not processed in metabolism. In fact, cyclamate, one of widely used sweeteners, is sweeter than sugar (sucrose) and cheaper. The acceptable daily intake of cyclamate regulated by the national agency of drug and food control, known as BPOM, in foodstuff like jam is $1000 \mathrm{mg} / \mathrm{kg}$. The aim of this study was to analyze cyclamate level in some jam samples compared to the acceptable daily intake regulated by Food and Drug Administration. This was a descriptive analytical study. The sampling technique used was puposive random sampling. There were 24 jam samples consisting of strawberry jam $(S)$, pineapple jam $(N)$, chocolate jam $(C)$ and blueberry jam $(B)$. The results showed that from twenty four jam samples indicated that there were six samples identified by $\mathrm{Nl}$, $\mathrm{C2}, \mathrm{N3}, \mathrm{C3}, \mathrm{B3}$ and C4 exceeding the acceptable daily intake (>1000 $\mathrm{mg} / \mathrm{kg}$ ).
\end{abstract}

Keywords: food additives, sweetener, cyclamate, jam

\footnotetext{
Alamat korespondensi:

Jl. Permata I No. 32 Pekanbaru
}

hartini.tini214@gmail.com 


\section{PENDAHULUAN}

Bahan Tambahan Pangan (BTP) adalah bahan yang ditambahkan ke dalam pangan untuk mempengaruhi sifat atau bentuk pangan (Peraturan Menteri Kesehatan Republik Indonesia, 2012). Banyaknya bahan tambahan pangan dalam bentuk murni dan tersedia dengan harga yang relatif murah mendorong meningkatnya konsumsi bahan tambahan pangan bagi setiap individu. Bahan tambahan pangan tersebut antara lain bahan pewarna, pengawet, anti gumpal, pemucat, dan pemanis (Cahyadi, 2009).

Bahan tambahan pangan berupa pemanis umumnya dikonsumsi oleh masyarakat yang menderita diabetes dan obesitas (Nadipelly, 2017). Hal tersebut bertujuan agar penderita dibetes dan obesitas tetap mendapatkan rasa manis pada makanannya tetapi tidak dimetabolisme di dalam tubuh (Chattopadhyay, Raychaudhuri and Chakraborty, 2014). Pemanis yang diperbolehkan di Indonesia mengacu pada Peraturan Kepala Badan Pengawas Obat dan Makanan Republik Indonesia Nomor 4 Tahun 2014. Pada peraturan tersebut terdapat dua kelompok pemanis yaitu pemanis alami (natural sweeteners) dan pemanis buatan (artificial sweeteners). Pemanis buatan yang diperbolehkan di Indonesia mengacu pada Peraturan Kepala Badan Pengawas Obat dan Makanan Republik Indonesia Nomor 4 Tahun 2014 (BPOM RI, 2014). Pada peraturan tersebut terdapat dua kelompok pemanis yaitu pemanis alami (natural sweeteners) dan pemanis buatan (artificial sweeteners). Pemanis alami antara lain sorbitol, manitol, glikosida steviol, laktitol dan silitol. Pemanis buatan antara lain aspartam, siklamat, sakarin dan sukralosa (Cahyadi, 2009).

Pemanis buatan salah satunya siklamat mempunyai tingkat rasa manis yang lebih tinggi dari gula (sukrosa) dan harganya lebih murah. Keunggulan tersebut menyebabkan produsen makanan banyak menggunakan siklamat sebagai bahan tambahan pangan khususnya sebagai pemanis pada selai. Hasil penelitian dari (Rahmi, 2018) menyatakan bahwa dari 4 sampel diperoleh 3 sampel positif mengandung siklamat dengan kadar 0,1048 gr $/ \mathrm{kg}, 0,0004 \mathrm{gr} / \mathrm{kg}$, dan $0,0657 \mathrm{gr} / \mathrm{kg}$. Selain itu, penelitian lain juga menunjukkan terdapat kandungan siklamat pada 3 sampel selai yang tidak bermerek. Kadar maksimum siklamat yang ditetapkan pemerintah melalui BPOM dalam suatu bahan pangan berupa selai (jem, jeli, marmalad) adalah $1000 \mathrm{mg} / \mathrm{kg}$ (BPOM RI, 2014). Meskipun pemerintah telah menetapkan peraturan mengenai kadar maksimum siklamat, tetapi masih saja ada produsen yang menggunakannya melebihi kadar yang diperbolehkan.

Penggunaan siklamat sebagai bahan tambahan pemanis buatan, selain dapat membantu menggantikan gula pada pasien diabetes dan obesitas ternyata siklamat juga memiliki dampak negatif. Dampak negatif siklamat dalam jangka pendek dapat menyebabkan mual, sakit kepala dan muntah. Adapun dampak negatif siklamat dalam jangka panjang adalah memicu timbulnya 
kanker, iritasi lambung dan perubahan fungsi sel (Cahyadi, 2009). Siklamat juga dilarang untuk ditambahkan pada produk pangan yang diperuntukkan bagi bayi, anak usia di bawah tiga tahun, ibu hamil dan/atau ibu menyusui. Keluhan kesehatan yang terjadi pada anak-anak yang mengonsumsi jajanan mengandung siklamat yaitu batuk, sakit perut, mual dan muntah (Hadiana, 2018).

\section{METODE}

Jenis penelitian yang digunakan adalah penelitian deskriptif analitik. Lokasi pengambilan sampel adalah pasar Dupa Pekanbaru. Teknik sampling yang digunakan pada penelitian adalah purposive sampling. Adapun kriteria pengambilan sampel terdiri dari kriteria inklusi dan eksklusi. Kriteria inklusi yaitu selai yang merupakan hasil produksi sendiri, sedangkan kriteria eksklusi yaitu selai yang terdaftar di BPOM. Sampel penelitian yaitu selai yang terdiri dari selai stroberi (kode S), nenas (kode N), coklat (C) dan blueberry (B). Keempat sampel diambil dari empat penjual yang berbeda (kode 1-4). Penelitian dilakukan di laboratorium kimia Akademi Kesehatan John Paul II Pekanbaru. Metode penelitian yang digunakan untuk menentukan kadar siklamat adalah metode gravimetri.

Alat-alat yang digunakan dalam penelitian ini adalah alat-alat gelas, timbangan digital merek Amstech, waterbath merek Memmert, Oven merek Memert, hot plate, kertas saring dan alat-alat gelas merek Pyrex, Vacum Jintengkeji Rocker 300. Bahan-bahan yang digunkan dalam penelitian ini adalah sampel selai, akuades, barium klorida $\left(\mathrm{BaCl}_{2} 10 \%\right)$, asam klorida $(\mathrm{HCl}$ $10 \%)$, natrium nitrit $\left(\mathrm{NaNO}_{2} 10 \%\right)$.

\section{Prosedur Kerja}

1. Pengujian Sampel Secara Kualitatif (Setiawan, Ibrahim and Wahab, 2016)

Sampel ditimbang sebanyak $25 \mathrm{~g}$ dan diencerkan menggunakan akuades $100 \mathrm{~mL}$ dengan perbandingan 1: 4. Tambahkan seujung spatula arang aktif untuk menghilangkan warna, kemudian sampel disaring. Tambahkan $10 \mathrm{~mL} \mathrm{HCl} \mathrm{10 \%} \mathrm{ke} \mathrm{dalam} \mathrm{filtrat} \mathrm{dan} \mathrm{ditambah}$ $10 \mathrm{~mL} \mathrm{BaCl}_{2}$ 10\%. Filtrat dibiarkan selama 30 menit kemudian filtrat disaring. Kemudian tambahkan $10 \mathrm{~mL} \quad \mathrm{NaNO}_{2} \quad 10 \%$. Larutaan dipanaskan di atas penangas air. Adanya endapan berwarna putih menunjukkan adanya siklamat.

2. Pengujian Sampel Secara Kuantitatif

Sampel ditimbang sebanyak $25 \mathrm{~g}$ dan diencerkan menggunakan akuades dengan perbandingan $1: 4$. Tambahkan seujung spatula arang aktif untuk menghilangkan warna, kemudian sampel disaring. Tambahkan $10 \mathrm{~mL} \mathrm{HCl} 10 \%$ ke dalam filtrat dan ditambah $10 \mathrm{~mL} \mathrm{BaCl}_{2}$ 10\%. Filtrat dibiarkan selama 30 menit kemudian disaring. Kemudian tambahkan $10 \mathrm{~mL} \mathrm{NaNO}{ }_{2} 10 \%$. Larutan dipanaskan di atas penangas air. 
Kemudian endapan yang terjadi disaring, dikeringkan didalam oven dengan suhu $100^{\circ} \mathrm{C}$ selama \pm 5 menit, dan ditimbang. Pengujian daya hambat

\section{HASIL DAN PEMBAHASAN}

Penelitian ini menggunakan 24 sampel selai yang dijual oleh 6 pedagang selai di Pasar Dupa Pekanbaru. Sampel diberi kode menggunakan huruf S (selai stroberi), N (selai nenas), C (selai coklat), B (selai blueberry) dan kode angka 1-6 untuk pedagang yang menjual selai mulai dari pedagang pertama hingga pedagang keenam. Uji kualitatif digunakan sebagai uji pendahuluan untuk menentukan keberadaan siklamat di dalam sampel selai.Uji kualitatif siklamat ditandai dengan terbentuknya endapan putih yang merupakan barium sulfat $\left(\mathrm{BaSO}_{4}\right)$ hasil dari reaksi antara natrium siklamat dengan barium klorida dan natrium nitrit serta adanya bau gas. Hasil uji kualitatif dapat dilihat pada Tabel 1.

\section{Tabel 1. Hasil uji kualitatif siklamat}

\begin{tabular}{cccl}
\hline Kode sampel & Hasil & Bau Gas & \multicolumn{1}{c}{ Keterangan } \\
\hline S1 & $(+)$ & Ada & Terbentuk endapan putih \\
N1 & $(+)$ & Ada & Terbentuk endapan putih \\
C1 & $(-)$ & Tidak ada & Tidak terbentuk endapan putih \\
B1 & $(-)$ & Tidak ada & Tidak terbentuk endapan putih \\
S2 & $(+)$ & Ada & Terbentuk endapan putih \\
N2 & $(+)$ & Ada & Terbentuk endapan putih \\
C2 & $(-)$ & Tidak ada & Tidak terbentuk endapan putih \\
B2 & $(-)$ & Tidak ada & Tidak terbentuk endapan putih \\
S3 & $(+)$ & Ada & Terbentuk endapan putih \\
N3 & $(+)$ & Ada & Terbentuk endapan putih \\
C3 & $(-)$ & Tidak ada & Tidak terbentuk endapan putih \\
B3 & $(+)$ & Ada & Terbentuk endapan putih \\
S4 & $(+)$ & Ada & Terbentuk endapan putih \\
N4 & $(+)$ & Ada & Terbentuk endapan putih \\
C4 & $(-)$ & Tidak ada & Tidak terbentuk endapan putih \\
B4 & $(+)$ & Ada & Terbentuk endapan putih \\
S5 & $(+)$ & Ada & Terbentuk endapan putih \\
N5 & $(+)$ & Ada & Terbentuk endapan putih \\
C5 & $(-)$ & Tidak ada & Tidak terbentuk endapan putih \\
B5 & $(-)$ & Tidak ada & Tidak terbentuk endapan putih \\
S6 & $(-)$ & Tidak ada & Tidak terbentuk endapan putih \\
N6 & $(+)$ & Ada & Terbentuk endapan putih \\
C6 & $(-)$ & Tidak ada & Tidak terbentuk endapan putih \\
B6 & $(-)$ & Tidak ada & Tidak terbentuk endapan putih \\
\hline Keterangan: & S adalah selai stroberi 1 adalah penjual pertama
\end{tabular}

adalah pedagang kelima

keenam

$\mathrm{N}$ adalah selai nenas 2 adalah penjual kedua 6 adalah pedagang

$\mathrm{C}$ adalah selai coklat $\quad 3$ adalah penjual ketiga

B adalah selai blueberry 4 adalah penjual keempat 
Berdasarkan tabel 1 hasil uji kualitatif siklamat menunjukkan bahwa terdapat 13 sampel selai yang positif mengandung siklamat dan 11 sampel selai yang tidak mengandung siklamat. Adapun persentase sampel yang positif mengandung siklamat sebesar 54,2\% dan sampel yang tidak mengandung siklamat sebesar $45,8 \%$.

Tabel 2. Hasil uji kuantitatif siklamat

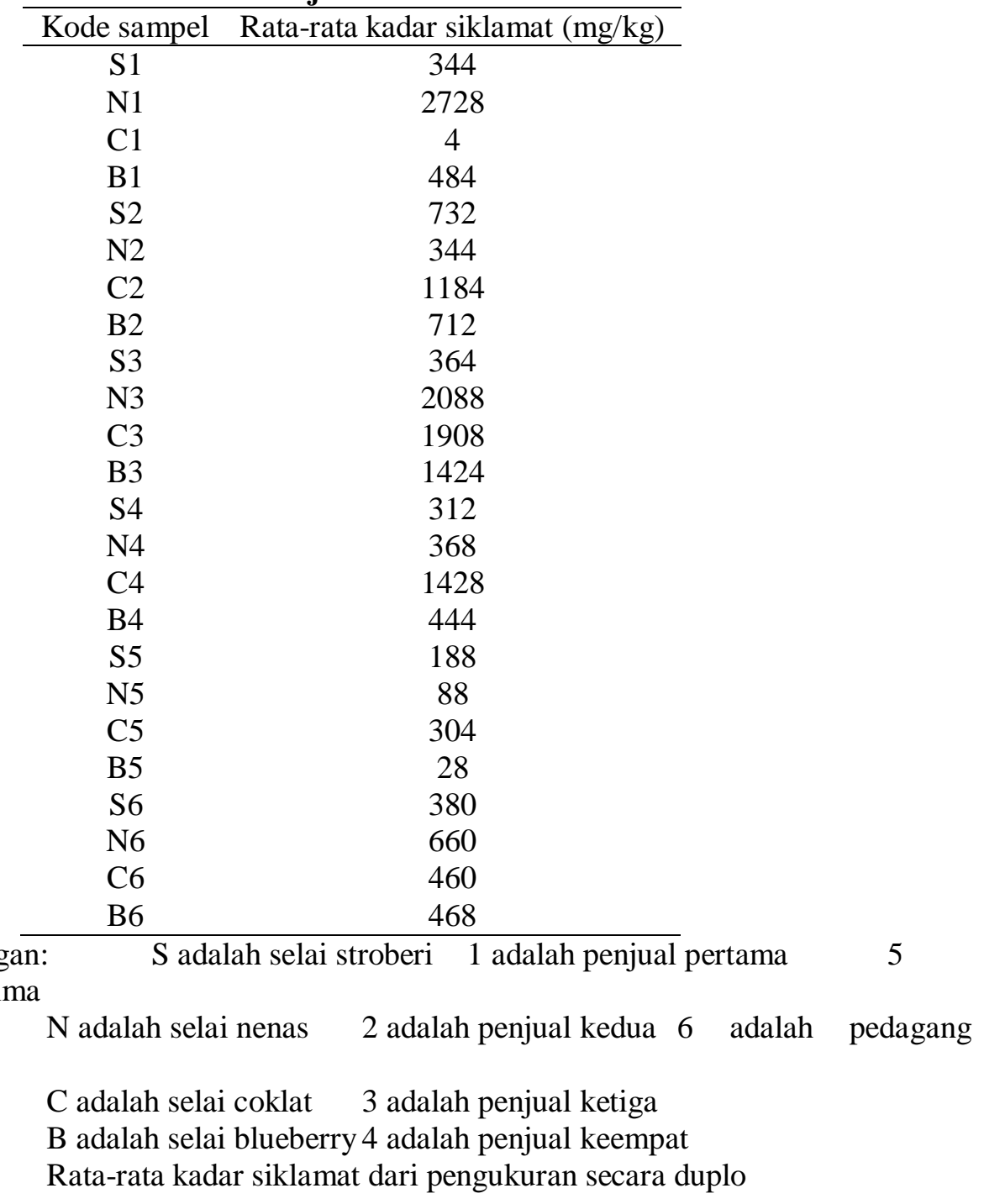

Uji kuantitatif dilakukan pada semua sampel (yang positif dan negatif pada uji kualitatif). Hal ini dilakukan untuk menentukan kadar siklamat yang terkandung di dalam sampel. Metode uji kuantitatif yang digunakan adalah metode gravimetri. Metode gravimetri merupakan metode yang digunakan untuk menentukan kuantitas suatu analit dengan pengendapan. Menurut Peraturan Kepala Badan Pengawas Obat Dan Makanan Republik Indonesia Nomor 4 Tahun 2014 tentang Batas Maksimum Penggunaan Bahan Tambahan Pangan Pemanis bahwa batas maksimum siklamat dalam bentuk asam siklamat di dalam selai (jem, jeli, marmalad) adalah $1000 \mathrm{mg} / \mathrm{kg}$ (BPOM RI, 2014). Hasil uji kuantitatif diperoleh 
bahwa seluruh sampel selai mengandung siklamat dengan kadar yang bervariasi. Mengacu pada hasil penelitian diperoleh bahwa sampel N1, C2, N3, C3, B3 dan C4 (terdapat 6 sampel) dengan kadar sikalamat yang dikandungnya berada diatas batas maksimum yang diperbolehkan dan 18 sampel lainnya berada dibawah batas maksimum.

Berdasarkan hasil uji kuantitatif yang dilakukan pada penelitian ini (tabel 2) diperoleh bahwa sampel N1 memiliki kadar siklamat tertinggi sebesar $2728 \mathrm{mg} / \mathrm{kg}$, selanjutnya C2 sebesar 1184 mg/kg, N3 sebesar 2088 mg/kg, C3 sebesar 1908 mg/kg, B3 sebesar 1424 mg/kg dan C4 sebesar $1428 \mathrm{mg} / \mathrm{kg}$. Kemungkinan rasa manis pada selai yang dijual pedagang selai N1, $\mathrm{C} 2, \mathrm{~N} 3, \mathrm{C} 3, \mathrm{~B} 3$ dan $\mathrm{C} 4$ sebagian besar berasal dari siklamat dan atau tanpa ditambahkan dengan pemanis alami seperti gula atau sukrosa. Sedangkan sampel dengan kode C1, N5, B5 memiliki kadar siklamat yang sedikit (1/10 dari kadar batas maksimum). Rasa manis yang terdapat pada sampel C1, N5 dan B5 tersebut berasal dari sedikit campuran siklamat dan pemanis alami.

Siklamat umumnya dikonsumsi oleh penderita diabetes dan obesitas (Polyák et al., 2010). Hal tersebut bertujuan agar penderita dibetes dan obesitas tetap mendapatkan rasa manis pada makanannya tetapi tidak dimetabolisme di dalam tubuh (Chattopadhyay, Raychaudhuri and Chakraborty, 2014). Meskipun memiliki tingkat kemanisan yang tinggi dan rasanya enak, tetapi siklamat djuga memiliki efek negatif bagi kesehatan (Pursitasari, 2014). Efek negatif siklamat antara lain merangsang pertumbuhan tumor, menyebabkan atropi yaitu pengecilan testikular dan kerusakan kromosom (Toora et al., 2018).

Sampel selai yang seluruhnya mengandung siklamat memperlihatkan bahwa produsen secara segaja menambahkan siklamat dalam proses produksi selai. Namun, umumnya produsen tersebut menambahkan siklamat dalam jumlah yang besar. Beberapa penyebabnya antara lain tidak mengetahui kadar batas maksimum siklamat dalam makanan, tidak mendapat sosialisasi peraturan Kepala BPOM Nomor 4 tahun 2014, tingkat pendidikan yang rendah dan tidak mengetahui efek yang ditimbulkan bagi tubuh (Nurlailah, Alma and Oktiyani, 2017).

\section{SIMPULAN}

Berdasarkan hasil penelitian yang diperoleh maka dapat disimpulkan bahwa dari 24 sampel selai diperoleh bahwa 13 sampel selai positif mengandung siklamat (terbentuk endapan putih dan bau gas) dan 11 sampel selai yang tidak mengandung siklamat (tidak terbentuk endapan putih dan tidak ada bau gas). Terdapat 6 sampel yaitu N1, C2, N3, C3, B3 dan C4 yang memiliki kadar siklamat melebihi kadar maksimum (1000 mg/kg) sedangkan 18 sampel lain kadar siklamatnya berada dibawah kadar maksimum.

\section{UCAPAN TERIMA KASIH}


Ucapan terima kasih kepada pihak terkait yang telah membantu dan bekerjasama demi kelancaran penelitian ini.

\section{DAFTAR PUSTAKA}

BPOM RI (2014) Batas Maksimum Penggunaan Bahan Tambahan Pangan Pemanis. Indonesia.

Cahyadi, W. (2009) Analisis dan Aspek Kesehatan Bahan Tambahan Pangan. 2nd edn. Edited by R. Rachmatika. Jakarta: Bumi Aksara.

Chattopadhyay, S., Raychaudhuri, U. and Chakraborty, R. (2014) 'Artificial sweeteners - A review', Journal of Food Science and Technology, 51(4), pp. 611-621. doi: 10.1007/s13197-011-0571-1.

Hadiana, A. B. (2018) 'Identifikasi Siklamat Pada Pangan Jajanan Anak Sekolah dan Keluhan Kesehatan', Jurnal Kesehatan Lingkungan, 10(2), pp. 191-200. doi: 10.20473/jkl.v10i2.2018.191-200.

Nadipelly, J. (2017) 'Role of Artificial Sweeteners in Development of Type 2 Diabetes mellitus (DM): A Review', Texila International Journal of Basic Medical Sciences, 2(2), pp. 63-70. doi: 10.21522/tijbms.2016.02.02.art009.

Nurlailah, N., Alma, N. A. and Oktiyani, N. (2017) 'Analisis Kadar Siklamat pada Es Krim di Kota Banjarbaru', Medical Laboratory Technology Journal, 3(1), p. 1. doi: 10.31964/mltj.v3i1.148.

Peraturan Menteri Kesehatan Republik Indonesia (2012) Bahan Tambahan Pangan.

Polyák, É. et al. (2010) 'Effects of artificial sweeteners on body weight, food and drink intake', Acta Physiologica Hungarica, 97(4), pp. 401-407. doi: 10.1556/APhysiol.97.2010.4.9.

Pursitasari, I. D. (2014) Kimia Analitik Dasar. Edited by A. Permanasari. Bandung: Alfabeta.

Rahmi, S. (2018) 'Analisis Pengawet Dan Pemanis Buatan Pada Selai Roti Yang Beredar Di Pasar Sekitar Kota Medan', Jurnal Penelitian Pendidikan MIPA, 3(1), pp. 217-225.

Setiawan, E. A., Ibrahim, M. N. and Wahab, D. (2016) 'Analisis Kandungan Zat Pengawet Natrium Benzoat Pada Sirup Kemasan Botol Yang Diperdagangkan Di Mall Mandonga Dan Hypermart Lippo Plaza Kota Kendari', J. Sains dan Teknologi Pangan, 1(1), pp. 2527-6271. doi: 10.6066/jtip.2016.26.1.1.

Toora, B. D. et al. (2018) 'Effect of Artificial Sweeteners on the Blood Glucose Concentration', Journal of Medical Academics, 1(2), pp. 81-85. doi: 10.5005/jp-journals-10070-0017. 